Original Article

\title{
Effect of acute and chronic coenzyme Q10 supplementation on creatine kinase after exhaustive aerobic activity
}

\author{
Parvaneh Valadbeigi ${ }^{1}$, Naser Behpour ${ }^{2 *}$, Vahid Tadibi ${ }^{2}$
}

\begin{tabular}{l} 
ARTICLE INFO \\
\hline Article History: \\
Received 1 January 2018 \\
Revised 7 January 2018 \\
Accepted 7 January 2018 \\
Published online 13 January 2018 \\
\hline
\end{tabular}

Keywords:

Coenzyme Q10;

Creatine Kinase;

Exhaustive Bruce test

${ }^{1}$ Graduated MA of Sports Physiology, Department of Physiology, Razi University, Kermanshah, Iran ${ }^{2}$ Sports Physiology, Department of Physiology Razi University Kermanshah, Iran

\section{Correspondence:}

Dr Naser Behpour

Department of Physiology, Razi

University Kermanshah, Iran

Email: n_behpoor@yahoo.com

\begin{abstract}
Introduction: Fatigue and muscle pain, is a common and prevalent experience after physical activity, especially exhausting activities. The purpose of this study was to investigate the acute and chronic effects of supplementation of coenzyme Q10 on creatine kinase after exhausting aerobic activity in soccer players.

Methods: Twelve male soccer players who did not have a history of muscular injury since six months ago volunteered to participate in the study. They were examined in three groups of acute, chronic and control. In order to induce muscle damage, a Bruce exhaustive test was performed and to determine the level of creatine kinase blood samples were taken before and after Bruce test. In the acute situation, one day before the Bruce test, two Q10 supplements (each $100 \mathrm{mg}$ ) and in chronic situation Bruce's test was performed after eight weeks of supplementation. To analyze the data, dependent $\mathrm{t}$-test was used at a significant level of $\mathrm{P}<0.05$.

Result: Diagnosis of muscle damage was assessed by measuring the biochemical changes of the creatine kinase enzyme. Statistical analysis showed no significant changes in the level of creatine kinase in acute situation ( $p>0.05$ ), but there was a significant decrease in chronic supplementation $(\mathrm{p}<0.05)$.

Conclusion: Coenzyme Q10 supplementation seems to improve the level of the main markers of muscle damage.
\end{abstract}

\section{Introduction}

$\mathrm{T}$ oday regularly participate in sport programs especially aerobic exercise is necessity to prevent diseases and improve the quality of life is (1). This is while, because of some kind of relatively intense exercise activity that leads to loss of acid-base balance (lactic acid accumulation) or oxidative stress indication it may cause loss of some physiological capacities, fatigue, and other subsequent consequences (Instability and damage of cell membranes) (2). A 30-minute run with $75 \%$ maximum oxygen consumption on a treadmill leads to increased blood lactate and total serum creatine kinase $(\mathrm{CK})$ (as an indicator of exercise pressure and cellular damage). Therefore, researchers and sports medicine specialists have always been looking for strategies to improve performance and to prevent unwanted fatigue related physiological capacity indices or at least to attenuate it to its lower level (5-3). Fatigue and muscle aches are common and prevalent experiences after physical activity (6). It's apparent, functional and biochemical symptoms, which have been studied in many studies, include muscle weakness, muscle stiffness, pain, 
inflammation, microscopic damages, accumulation of CK enzyme and lactate dehydrogenase in plasma (7). Symptoms usually occur 12 to 24 hours after exercise, and usually are not pleasant to people (8). The prevention and treatment of delayed muscle soreness is an unresolved and controversial issue, in which, as much as theories on the mechanism of soreness, various therapies are provided for it (7). The use of antioxidant supplements is one of the methods for preventing delayed muscle soreness. One of the ways to cope with undesirable effects of fatigue and the pressures caused by relatively intense exercise is using oral supplementation such as the Q10 enzyme or the Ubiquinol (9). Coenzyme Q10 is a fat-soluble vitamin-like, which carries electrons in the mitochondria (10) and has antioxidant properties (6). The Q10 enzyme can prevent delayed muscle soreness by preventing free radicals. Hence, some researchers believe that the use of coenzyme Q10 supplementation can prevent some adverse changes in some of the biochemical indices caused by energy loss during exercise activities.

For example, Kon et al. In confirmation of the results of Shimomura et al., Stated that the coenzyme Q10 supplementation as an anti-oxidative and anti-fatigue supplement can prevent undesirable changes in serum total lactate and CK after relatively heavy exercise (53 ). Given the limited and controversial studies on coenzyme Q10 supplementation with exercise activities still, the question is whether the short-term and long-term co-enzyme Q10 supplementation can reduce muscle damage caused by intense physical activity? Therefore, the present study aimed to determine the effects of acute and chronic co-enzyme supplement Q10 (200 mg / day) on CK following the Bruce's exhaustive test in young footballers.

\section{Methods}

\section{Study design and population}

The research was carried out in a semi-experimental design with repeated measurements (six steps). The statistical population of the present study was Kermanshah Besat youth football team. The age range of the subjects was 17-19 years with at least 1 year of regular exercise, no use of any drug and supplement, non-smoker, and the ability of a regular company to the research were criteria for entering the study. Suffering from any illness or acute discomfort during the study, the voluntary withdrawal of participants from the study, the lack of supplementation and incidence of acute injury caused by the practice during the study were exclusion criteria. After initial coordination with the club, 12 volunteers were selected. A week before the start of the project, a briefing session was held with the subjects to get them acquainted with the type of supplement and its effects. Brochures and complete information about the supplement, as well as the personal information questionnaire, were provided to individuals in this session. Restrictions was discussed on the use of other supplements and drugs affecting the study, including other antioxidant supplements, such as vitamin E and $\mathrm{C}$, smoking, caffeine, and other drugs. Subjects were also provided with explanations on how and when they should use supplement. On the morning of the test, the subjects attended the laboratory of the Faculty of Physical Education at Razi University of Kermanshah. At first, the anthropometric characteristics (height, weight and body mass index) were measured. Subjects were then assigned to control and supplementation (200 mg / day) groups according to the age (17-19 years), weight (63 to $72 \mathrm{~kg}$ ), height (170 to $184 \mathrm{~cm}$ ) and body mass index $(18-23 \mathrm{~kg} / \mathrm{m} \mathrm{2})$.

Step 1: To determine the acute supplementation effect, before implementing the protocol that cause muscle soreness, $5 \mathrm{ml}$ of blood was drawn from the basilic vein to evaluate the serum CK baseline. Then, muscle soreness protocol was performed, according to which each subject performed Bruce's exhaustive testing and the second blood sampling was done. The study of the difference between the two-time valuation of $\mathrm{CK}$ determines the effect of Bruce's exhaustive test. In the next position, Bruce test was performed one day after taking two Q10 coenzyme supplements (each 100 $\mathrm{mg}$ ). Blood samples were taken before and after the Bruce test, and by studying their difference CK response was determined and it was compared with the previous response.

Step 2: In order to determine the chronic effect of the supplement, each person was given 112 Q10 coenzyme (each $100 \mathrm{mg}$ ) to consumed two of them daily after lunch. In order to ensure supplementation, the subjects were reminded every day by using the SMS system. One day after the end of 8 weeks of supplementation, before the implementation of the protocol of muscle soreness, $5 \mathrm{ml}$ of blood was drawn from the basilic vein of the subjects to evaluate the baseline level of serum CK index. After performing Bruce's exhaustive testing to create muscle soreness, the $\mathrm{CK}$ variable was re-measured as one of the main signs of soreness. The subjects in this study were football players who were all members of the Behsat team. Therefore, during the course of the research, they had the same trainings, which were 4-5 days of week And 48 hours before the Bruce protocol they had no training in three acute and chronic and control 
groups. Supplementation was with Q10 Capsules from International Agencies Company of United States of America (Health Promotion No. 302012061035, Food and Drug Administration, Department of Health and Medical Education. Exclusive importer in Iran: Pourateb Pharmaceuticals Company. Supplement was provided from drug stores of Iran. This supplement contains 30 capsules $(100 \mathrm{mg})$; it is a product of 2014. The activity of serum creatine kinase enzyme was determined with the CK kits of the Pishtaz Teb Company and the autoanalyzer device (Sinnowa biochemistry) and was measured according to the manufacturer's instructions. Samples were centrifuged at $4000 \mathrm{rpm}$ for 5 minutes. All measurements were made in the same conditions of ventilation and light at 09:00 to 11:30 o'clock in the morning. In addition, the subjects had to avoid any heavy physical activity 48 hours prior to the test, and their meals were similar before the test.

\section{Bruce exhaustive test}

Bruce's test was taken from subjects in order to induce muscle damage in subjects. The Bruce Test (running on the pulsar med 3p model treadmill manufactured by the $\mathrm{h} / \mathrm{p}$ cosmos company (Germany)) started at 1.7 mph $(2.74 \mathrm{kph})$ and a gradient of $10 \%$. Then, at each level, $1.3 \mathrm{~km} / \mathrm{h}, 2 \%$ gradient was added to the machine $(1,10)$. To diagnose exhaustion during the test, we spoke with participants until they said they are no longer able to continue the test.

\section{Ethical consideration}

This study has been approved by the Department of Physical Education and Sports Sciences of Razi University of Kermanshah with code 2338299. Before the implementation of the study, it was fully explained to the participants. An informed consent form was also received from them.

\section{Statistical analysis:}

Descriptive statistics was used to describe the central tendencies (mean) and scattering tendencies (standard deviation). First, Kolmogorov-Smirnov test was used for data normalization. Dependent $t$ was used to evaluate the difference between pre-test and post-test in each group. Dependent $t$ was also used to determine the variation level at each stage. All calculations were done using SPSS software version 20 and Excel software was used for drawing graphs and tables; in all cases, the significance level of the statistical data was considered as $\mathrm{P} \leq 0.05$.

\section{Results}

The mean and standard deviation of individual characteristics including age, weight, height, and body mass index are shown in Table 1 and the results of CK index during the six measurement steps are shown in Table 2. The level of CK enzyme changes is shown in three acute and chronic and control groups in Table 3. Regarding the results, it can be seen that Bruce's exhaustive test makes a significant increase in serum $\mathrm{CK}$ in three acute and chronic and control groups $(\mathrm{P} \leq$ $0.05)$ (Figure 1). According to the results, one-day supplementation of Q10 (200 mg) and its comparison with the control stage did not significantly change the level of $\mathrm{CK} \quad(\mathrm{P}>0.05)$. However, the 8-week supplementation of Q10 significantly reduced serum CK levels $(\mathrm{P}<0.05)$ (Figure 2).

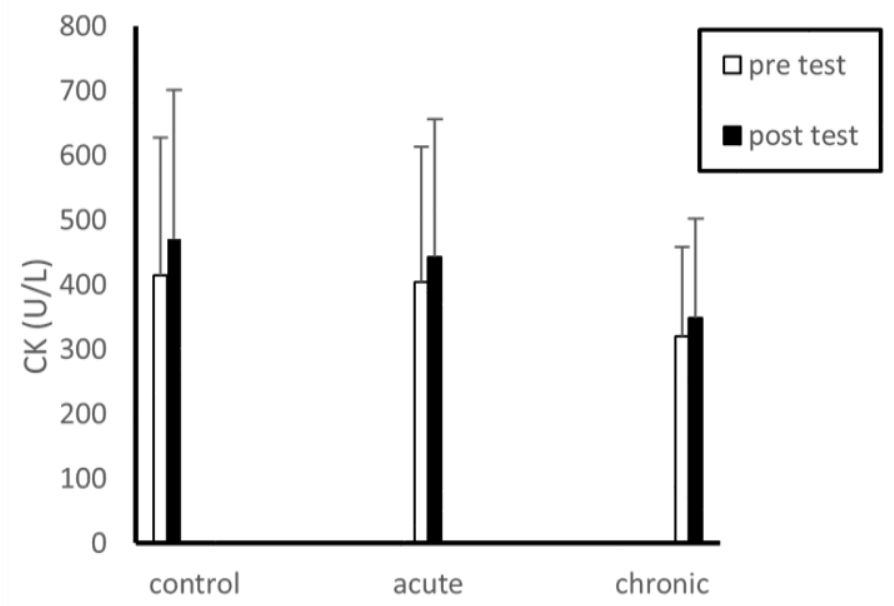

Figure 1: Comparison of pre-test and post-test CK (U/L) in in three phase of acute and chronic and control and

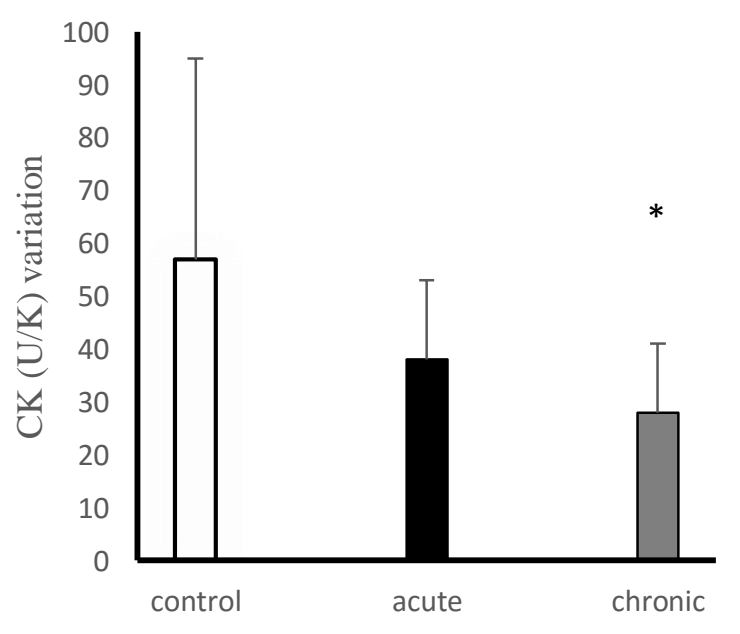

Figure 2: Comparison of $\mathrm{CK}(\mathrm{U} / \mathrm{L})$ changes in three phase of acute and chronic and control * $(\mathrm{P} \leq 0.05)$ 
Table 1: Descriptive information about subjects

$\begin{array}{ccccc}\text { Variable } & \text { Minimum } & \text { Maximum } & \text { Mean } & \text { SD } \\ \text { Age } & 17 & 19 & 18.8 & 0.79 \\ \text { Height } & 170 & 184 & 178.8 & 3.82 \\ \text { Weight } & 63.9 & 75.5 & 68.77 & 2.95 \\ \text { BMI } & 18.87 & 24.98 & 21.73 & 1.65\end{array}$

Table 2: Mean and standard deviation of CK index in six stages of measurement

\begin{tabular}{|c|c|c|c|c|c|}
\hline Stage & $\begin{array}{l}\text { Measurement } \\
\text { time }\end{array}$ & Number & Mean & SD & $P$ value \\
\hline \multirow{3}{*}{ Acute } & Pre-test & \multirow{2}{*}{12} & 414.83 & 213.5 & 0.200 \\
\hline & Post test & & 471.250 & 230.40 & 0.062 \\
\hline & Pre-test & \multirow{3}{*}{12} & 404.916 & 210.59 & 0.200 \\
\hline \multirow[t]{3}{*}{ Chronic } & Post test & & 443.583 & 213.94 & 0.186 \\
\hline & Pre-test & & 320.250 & 139.19 & 0.200 \\
\hline & Post test & 12 & 343.000 & 154.03 & 0.200 \\
\hline
\end{tabular}

Table 3: Levels of CK enzyme changes (U/L) in the control and chronic phase

\begin{tabular}{|c|c|c|c|}
\hline Index & Measurement phase & Changes level & $P$ value \\
\hline \multirow{2}{*}{ Creatine kinase (U/L) } & $\begin{array}{l}\text { Control } \\
\text { Acute }\end{array}$ & $\begin{array}{l}57.166 \pm 38.34 \\
38.66 \pm 15.47\end{array}$ & 0.063 \\
\hline & $\begin{array}{l}\text { Control } \\
\text { Chronic }\end{array}$ & $\begin{array}{l}57.166 \pm 38.34 \\
28.75 \pm 13.51\end{array}$ & 0.010 \\
\hline
\end{tabular}

\section{Discussion}

The results of the study obtained during the threeposition control bleeding, acute and chronic, indicate that a session of aerobic exhausting activity on the treadmill causes significant increase in $\mathrm{CK}$ as an indicator of muscle damage (Figure 1). It is concluded that acute supplementation of Q10 does not prevent significant increase in CK concentration in athletes (Figure 2). Also, the results of this study indicate that the 8-week supplementation of Q10 suppresses and inhibits significant increase of the concentration of CK in athletes. Many research had been carried out in this area, which this study is consistent with some of the researches and is not consistent with others. The present study is consistent with the study of Armanfar on the effect of 1-day supplementation of Q10 (200 mg) on CK induced by muscle damage (11) and is not consistent with Changizi research (12). The findings of the present study on the lack of effect of Q10 supplementation on the range of serum CK of male footballers following an exhausting aerobic activity (Bruce) is consistent with results of Armanfar and colleagues (11). Accordingly, supplementation of 200 milligrams of Q10 daily may not be able to prevent changes induced by the mechanical and metabolic pressure of intense aerobic exercise in footballers. In other words, the effects of this type of supplementation are not that much to prevent cellular 
energy upgrade from perforation or sarcoma injury. In a study by Changizi et al., The effect of acute supplementation of Q10 on some of the serum muscle injury parameters in men athletes was examined following a resistance training session. The results showed that CK concentration was significantly lower in Q10 supplementation group than placebo group. A session of resistance activity with $75 \%$ of 1RM severity significantly increased $\mathrm{CK}$ as an index of oxidative activity in the placebo group. In their study, the acute supplementation of Q10 caused modifying and preventing a significant increase in CK concentrations in athletes (12). In some previous studies, CK enzyme increasing was used as an indicator for evaluation of muscle cell damage after exercise (13). On the other hand, studies have shown that performing intense and prolonged exercises, regardless of the proper recovery time, can damage the muscle fibers during contractions, internal degradation of the skeletal muscle and connective tissues and with an inflammatory response, macrophage infiltration, cytosolic enzymes and myositoplasmic muscle fibers, CK enzymes release happens and following them pain symptoms, motor limitation and biochemical changes and muscle spasm will come $(13,14)$. At the same time, the increase in $\mathrm{CK}$, especially during the training and recovery, reflects the secretion of proteins and possibly other substances through the muscle membrane. In addition, factors such as age, sex, physical fitness, season, and training needs are associated with increased oscillations of this enzyme $(15,16)$. Among the possible mechanisms and theories of action through which resistance exercises can produce oxidative stress, theory of "damage to an ischemic re-injection" suggests that severe muscle contractions may result in a temporary decrease in blood flow and the availability of oxygen and results in ischemia. After contractions (the muscle expansion stage), re-injection of blood causes an excessive supply of oxygen and, consequently, the production of free oxygen radicals (17). In this study, Bruce's test was performed one day after 8 weeks of administration of 112 supplements of Q10 (100 mg). Blood samples were taken before and after Bruce test, and by studying their differences, significant differences was observed in the level of CK in subjects. This result is consistent with Kon et al. (2007), Shimomura et al. (1991) and Kon et al. (2008) (5-3). Kon et al. (2008) examined the effect of antioxidant supplementation of 300 milligrams of Q10 each day for 20 days on muscle damage and oxidative stress during exercise on 18 athletes and showed that CK was less in the supplement group than placebo. The result is that Q10 supplementation reduces exercise-induced muscle damage in athletes (4). Kon et al. (2007) investigated the effect of Q10 supplementation on oxidative stress and exerciseinduced damage on skeletal muscle and liver of rodents. The results of their research showed that the supplementation of Q10 increased the concentration of total Q10 in the slow twitch muscle of rodents and, by increasing the muscle membrane stability, it is effective in reducing muscle damage caused by exhausting exercise (3). In spite of the above results, Zuliani et al. (1989), in a study of 12 non-athlete students, indicated that one month of supplementation (100 mg Q10 daily) had no effect on the metabolism and oxidative indices, especially blood lactate and total CK (after two moderate activity On the gauge (9). Existing contradictions may be due to several factors, including the extent and amount of supplementation before activity, the amount and rate of absorption of supplements during the diet of the subjects before and during the study and the training status of the participants and a combination of the above factors, and it could affect the use of Antioxidant supplements effect on the response of oxidative indices; Because according to the available studies, the daily intake of Q10 (due to a half-life of 33 hours and high molecular weight and its hydrophobicity property) it should be at least $2.5 \mathrm{mg}$ per $\mathrm{kg}$ of body weight in a single dose To receive plasma level of $2.5 \mu \mathrm{g} / \mathrm{ml}$ of minimum beneficial level to improve cardiovascular function $(18,19)$. (In the current study, the dose is $200 \mathrm{mg}$ /day which is more than the recommended dose). While in some studies, lower supplemental doses have been used.

\section{Conclusion}

Considering the significant increase in $\mathrm{CK}$ concentration, which is the main marker of muscle damage, it seems that even a session of exhausting aerobic activity can cause muscle damage. The longterm supplementation of Q10 (200 mg per person per day) as an anti-fatigue and antioxidant supplement can reduce the adverse effects of the CK enzyme on male soccer players after a session of exhausting aerobic exercise on the treadmill. It seems that supplementation factor and duration of use play a more important role in the results. Evidence suggests that future studies examine the different doses of this supplement and other related enzymes.

\section{Ethical disclosure}

Before performing the research, it was explained to the participants. An informed consent was obtained from all participants included in the study. 


\section{Aknowlagement}

This article is brought forth from the Master's thesis of Exercise Physiology approved by the code 2338299 from the Faculty of Physical Education and Sports Sciences of Razi University of Kermanshah. Hereby we Thank and gratitude to everyone who helped us with this research.

\section{Author Contributions}

All the authors have accepted responsibility for the entire content of this submitted manuscript and approved submission.

\section{Conflict of Interest}

The authors declare that they have no conflict of interest.

\section{Funding/Support}

None declared.

\section{References}

1. Ehrman JK. American College of Sports Medicine. ACSM'sresource manual for Guidelines for exercise testing and prescription. 6th ed. Philadelphia: Wolters Kluwer Health/Lippincott Williams \& Wilkins. 2010; pp 2-84.

2. Fu X, Ji R, and Dam J. Antifatigue effect of coenzyme Q10 in mice. J Med Food. 2010;13:211-5.

3. Shimomura Y, Suzuki M, Sugiyama S, Hanaki Y, and Ozawa T. Protective effect of coenzyme Q10 on exerciseinduced muscular injury. Biochem Biophys Res Commun. 1991;176:349-55.

4. Kon M, Kimura F, Akimoto T, Tanabe K, Murase Y, Ikemune S, Kono I. Effect of Coenzyme Q10 supplementation on exercise-induced muscular injury of rats. Exerc Immunol Rev. 2007;13:76-88.

5. Kon M, Tanabe K, Akimoto T, Kimura F, Tanimura Y, Shimizu K. Reducing exercise- induced muscular injury in kendo athletes with supplementation of coenzyme Q10. Br J Nutr. 2008;100,903-909. doi:10.1017/S0007114508926544

6.Nejatmand N, Ramezani A, Barati A. Effect of Consumption short-term CoQ10 supplementation on markers of delayed onset muscle soreness. RJMS. 2014;21(119) ,77-85.

7. Behpoor N, Rahimi N. Study and comparison of Ultrasound and Ice massage effect on delayed onset muscle soreness (DOMS) signs. J Sport. Pec. 2010; 8:15-26.

8. Meir M, Dumke CL and Urbiztondo ZU. Relationship between serum creatine kinase activity following exerciseinduced muscle damage and muscle fibrecompositin. J Sports Sci. 2010;28(3):257-66. doi:10.1080/02640410903440892

9. Zuliani U, Bonetti A, Campana M, Cerioli G, Solito F, Novarini A. The influence of ubiquinone (CoQ10) on the metabolic response to work. J Spo Med Phys Fit. 1989;29(1):57-62.
10. William JV, Stogsdill WW, Judy DS. Coenzyme Q10 facts or fabrications. Natural Products INSIDER. 2007; 2: 1 -4 .

11. Armanfar M, Jafari A, Dehghan Gh.R, Abdizadeh L. Effect of coenzyme Q10 supplementation on exerciseinduced response of inflammatory indicators and blood lactate in male runners. Med J Islam Repub Iran. 2015;29:202.

12. changizi M. Ebrahimi M. Avandi M. Acute effects of coenzyme Q10 supplement on serum parameters of oxidative stress following one session of resistance training in male college athlete. J Koomesh. 2015(4):603-610.

13. Andersson H, Bøhn SK, Raastad T, Paulsen G, Blomhoff R,Kadi F. Differences in the inflammatory plasma cytokine response following two elite female soccer games separated by a 72-h recovery. Scand J Med Sci Sports. 2010;20(5):740-7. doi: 10.1111/j.16000838.2009.00989.x

14. Aslan R,sekeroglu.M.R,Tarakcioglu M,Bayiroglu F,Meral I. Effect of acute regular exercise on antioxidative enzymes,tissue damage markers and membrane lipid per oxidation of erytrocytes in sedentary students. Tr J Med Sci. 1996;28,411-414.

15. Beal MF. Neurochemistry and toxin models in Huntington's disease. Curr Opin Neurol.1994;7(6):542547.

16. Belardinelli R, Muçaj A, Lacalaprice F. Coenzyme Q10 and exercise training in chronic heart failure. Eur Heart J. 1985;27(22):2675-2681. doi: 10.1093/eurheartj/ehl158 17.Bhaskar PA, Raut SE, Hawaldar VB. The effect ofexercise on platelet aggregagability and other cardiovascular parameters. Inte J of Basic Med Sci. 2012; $6(2): 27-41$

18. Cooke M, Iosia M, Buford T, Shelmadine B, Hudson G, Kerksick C, et al. Effects of acute and 14-day coenzyme Q10 supplementation on exercise performance in both trained and untrained individuals. J Int Soc Sports Nutr. 2008. 5:8. doi: 10.1186/1550-2783-5-8

19. Littarru GP, Tiano L.Bioenergetic and antioxidant properties of coenzyme Q10: recent developments. Mol Biotechnol. 2007; 37:31-7. doi: 10.1007/S12033-007$0052 \mathrm{y}$ 